\title{
Nutrition for the Next Generation: Older Children and Adolescents
}

\author{
Jai K. Das ${ }^{\text {a }}$ Zohra S. Lassi $^{b}$ Zahra Hoodbhoy a Rehana A. Salama, c \\ aDivision of Women and Child Health, Aga Khan University, Karachi, Pakistan; ${ }^{b}$ Robinson Research Institute, \\ University of Adelaide, Adelaide, SA, Australia; ' $S o u t h$ Australian Health and Medical Research Institute, University \\ of Adelaide, Adelaide, SA, Australia
}

\section{Key Messages}

- It is critical to ensure adequate nutrition for children and adolescents as this is intrinsically linked to the health of future generations.

- There is a need to make specific guidelines for nutrition requirements and interventions for older children and adolescents across various contexts, including low- and middle-income countries (LMICs).

- There is a need for more evidence around determining the most effective strategies to tackle the rising burden of overweight and obesity, especially from LMICs.

\section{Keywords}

Adolescents · Older children · Nutrition · Undernutrition . Overweight · Obesity · Nutrition interventions

\footnotetext{
Abstract

This paper reviews information on why the nutrition of older children (5-9 years) and adolescents (10-19 years) is important and the consequences that it can have over generations. Developing countries still face a high burden of undernutrition and anemia, while the burden of overweight and
}

obesity is on the rise in both developing and developed countries. There are evidence-based interventions which can improve the nutritional status and these include interventions for a balanced and diverse diet and micronutrient supplementation, especially iron and multiple micronutrient supplementation where there is sufficient evidence to reduce anemia. There is mixed evidence for the effective strategies to prevent and control obesity and a dearth of evidence from developing countries. Adolescent pregnancy also poses greater challenges to the health of mother and child, and advocacy should be rampant to delay the age of marriage and pregnancy. Interventions targeted to improving the nutritional status among "pregnant adolescents" have shown improvement in birth weight and a reduction in low birth weight and preterm delivery. Traditional platforms including school-based and community-based approaches offer a mixed picture of effectiveness, but emerging avenues of mHealth and social media could also be channelized to reach this population. The population of this age group is on the rise globally, and failure to invest in improving the nutrition of older children and adolescents will further increase the number of dependents in coming generations and negatively influence the health of future generations and progress of nations.

(c) 2018 S. Karger AG, Basel

\section{KARGER}

(c) 2018 S. Karger AG, Basel 
Fig. 1. Intergenerational effects of malnutrition. Adapted from the ACC/SCN-appointed Commission on the Nutrition Challenges of the 21st Century.

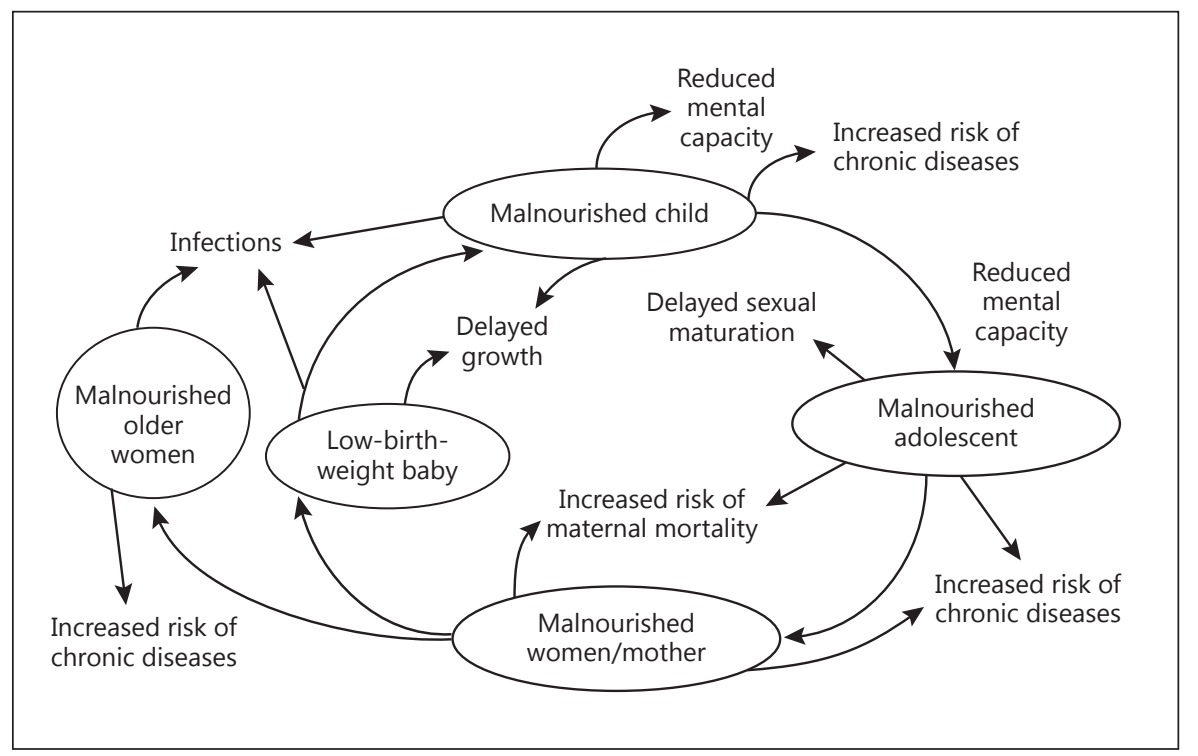

\section{Background}

Malnutrition encompassing both under- and overnutrition is a major public health crisis for children and adults across the world [1]. Developing countries are now facing the "double burden" of undernutrition and overweight and obesity [2], as the prevalence of overweight and obesity in children and adolescents has increased from $8.1 \%(7.7-8.6)$ in 1980 to $12.9 \%(12.3-13.5)$ in 2013 for boys and from $8.4 \%(8.1-8.8)$ to $13.4 \%(13.0-13.9)$ in girls [3]. And during the same period, the prevalence of overweight and obesity has increased remarkably in developed countries: from $16.9 \%(16.1-17.7)$ in boys and $16.2 \%$ (15.5-17.1) in girls in 1980 to $23.8 \%$ (22.9-24.7) in boys and $22.6 \%(21.7-23.6)$ in girls in 2013 [3]. There is also a high burden of undernutrition in developing countries and protein-energy malnutrition is responsible for 225,906 deaths (uncertainty level: 168,497-280,129) in children and adolescents aged 0-19 years [4]. Iron deficiency anemia is the leading cause of years lived with disability among children and adolescents, accounting for 619 million (uncertainty level: 618-621 million) prevalent cases in 2013 [4].

Pregnancy in adolescence poses additional risks to the mother and newborn, as adolescent girls are not physically mature enough, and undernutrition further exacerbates these risks. The common risks during adolescent pregnancy include anemia, stillbirth, prematurity, and mortality. It is estimated that around $10 \%$ of the global total births occur to adolescent girls between the age of 15 and 19 years [5]. And around three-quarters of these adolescent pregnancies occur in developing countries [5]. Stunted adolescents have further risks of obstetric complications, including obstructed labor and weakened physical capacity [6].

The major global focus of health has been on children under the age of 5 years and pregnant women, while older children (aged 6-9 years) and adolescents (aged 10-19 years) have not received the due attention until lately. Alleviating malnutrition in this age group requires a complex, multifactorial approach and thus addresses a major public health concern.

\section{Consequences of Undernutrition across the Life Course}

The nutritional issues of undernutrition and overnutrition among children and adolescents in developing countries are intricately woven together in an intergenerational cycle of malnutrition.

It is essential that women, particularly girls, are nourished well at all stages of growth and development because the risk of malnutrition in women spans a life cycle and also across generations, termed as intergenerational effects of malnutrition [7]. Any nutritional deficiency experienced during this critical period of life can have an effect on the future health of the individual and their offspring (Fig. 1). 
Addressing nutritional deficiencies in women and girls via life cycle approach can improve their nutritional status. Nutritional deficiencies experienced early on such as in utero, infancy, and childhood have consequences into the adult life. Stunting is often rooted from inadequate fetal growth [8] and it also influences the childhood cognitive tests and educational achievement [9]. Changes in in utero nutritional environment are associated with hampered growth and development and increased risk of developing cardiovascular and metabolic disorders in adult life [10]. The same vicious cycle of malnutrition is repeated in children of mothers who were malnourished.

Women, in general, are more likely to suffer from nutritional deficiencies than men because of their reproductive biology. However, children and adolescents in developing countries suffer the most with additional underlying factors including poverty, illiteracy, poor social status, and disparity in society. Today, approximately $468 \mathrm{mil}-$ lion nonpregnant women in low- and middle-income countries (LMICs) and half of all the pregnant women are anemic $[11,12]$. Poor nutritional status increases the risks for morbidity and mortality. For women, anemia is an underlying cause in approximately $20 \%$ of maternal deaths [13] and being underweight increases the chances of being stunted and that increases the risk for obstetric complications such as obstructed childbirth $[14,15]$. At a macro-level, malnourishment hinders work capacity and leads to further economic disadvantages.

\section{Physiology and Metabolism}

Malnutrition is the single most common reason for growth retardation. Inadequate nutrition in the early life of a child can delay sexual maturation and physical growth, which is necessary to reach the full development potential as an adult. For a girl, this is also important to prepare for her nutritional demands during pregnancy and lactation in adulthood. There are no standardized anthropometric measures for adolescents [16], and consequently various definitions are used by different studies to measure the burden of underweight and overweight in adolescents, thus hampering the determination of the actual burden of adolescent malnutrition.

The nutritional status has a significant contributing effect on the timing of adolescent sexual maturation, and it is well documented that undernutrition is associated with delayed age of menarche [17]. The growth spurt in adolescence requires rapid tissue expansion with special nutrient requirements, thus it is necessary to ensure that energy and nutrition requirements match the adolescent needs. Approximately half of an adult's ideal body weight is gained during adolescence, and approximately $20 \%$ of adult height is gained during the adolescent age period and most of this is gained rapidly $1-2$ years preceding the early stages of sexual maturation [16]. Malnutrition prevents individuals from attaining normal bone structure, strength, and development, and the onset of puberty is delayed in adolescents who are undernourished. This can allow for a longer time to catch up on growth, although there are deliberations on whether young adolescents who are stunted can catch up to their optimal height.

Older children and adolescents are particularly at risk of malnutrition because they experience the growth spurt and need all essential macro- and micronutrients to support the increased demand of the body for attaining puberty and development. Therefore, it is important that children and adolescents, particularly girls, are fed properly and are given all required micronutrients. Young girls who become pregnant during this phase are at greater risk of various complications since their body is supporting their own growth and that of the growing fetus; and the still-growing adolescent mother and her baby may compete for nutrients and increase the infant's risk of low birth weight and early death [18].

This age group also needs iron for their increased physiologic requirements for growth. Infectious diseases, such as malaria and hookworm, and menstruation in females can also affect iron absorption, use, and loss in adolescents and frequently contributes to iron deficiency. Malaria-related inflammation also reduces iron absorption and incorporation into red blood cells [19].

There is an increase in appetite in this age group and individuals with a sedentary lifestyle have a greater chance to accumulate fat, which contributes greatly to overweight and obesity, especially if they consume high-energy food. The caloric requirement of adolescent males is higher than that of adolescent females, owing to greater increases in height, weight, and lean body mass. Table 1 shows the Dietary Reference Intakes (DRIs) and Adequate Intakes (AIs) for adolescents as recommended by the Institute of Medicine and includes recommendations on energy requirements and requirements for various macro- and micronutrients [20].

\section{Long-Term Health Impacts of Malnutrition}

Malnutrition in women contributes to the growing burden of cardiovascular and other noncommunicable diseases. Undernutrition leads to numerous physiological and social alterations and is partly due to epigenetic
58

Ann Nutr Metab 2018;72(suppl 3):56-64 DOI: $10.1159 / 000487385$
Das/Lassi/Hoodbhoy/Salam 
Table 1. Examples of population reference nutrient intakes (vitamins and minerals): Dietary Reference Intakes (DRIs) and Adequate Intakes (AIs) for adolescents in the USA [20]

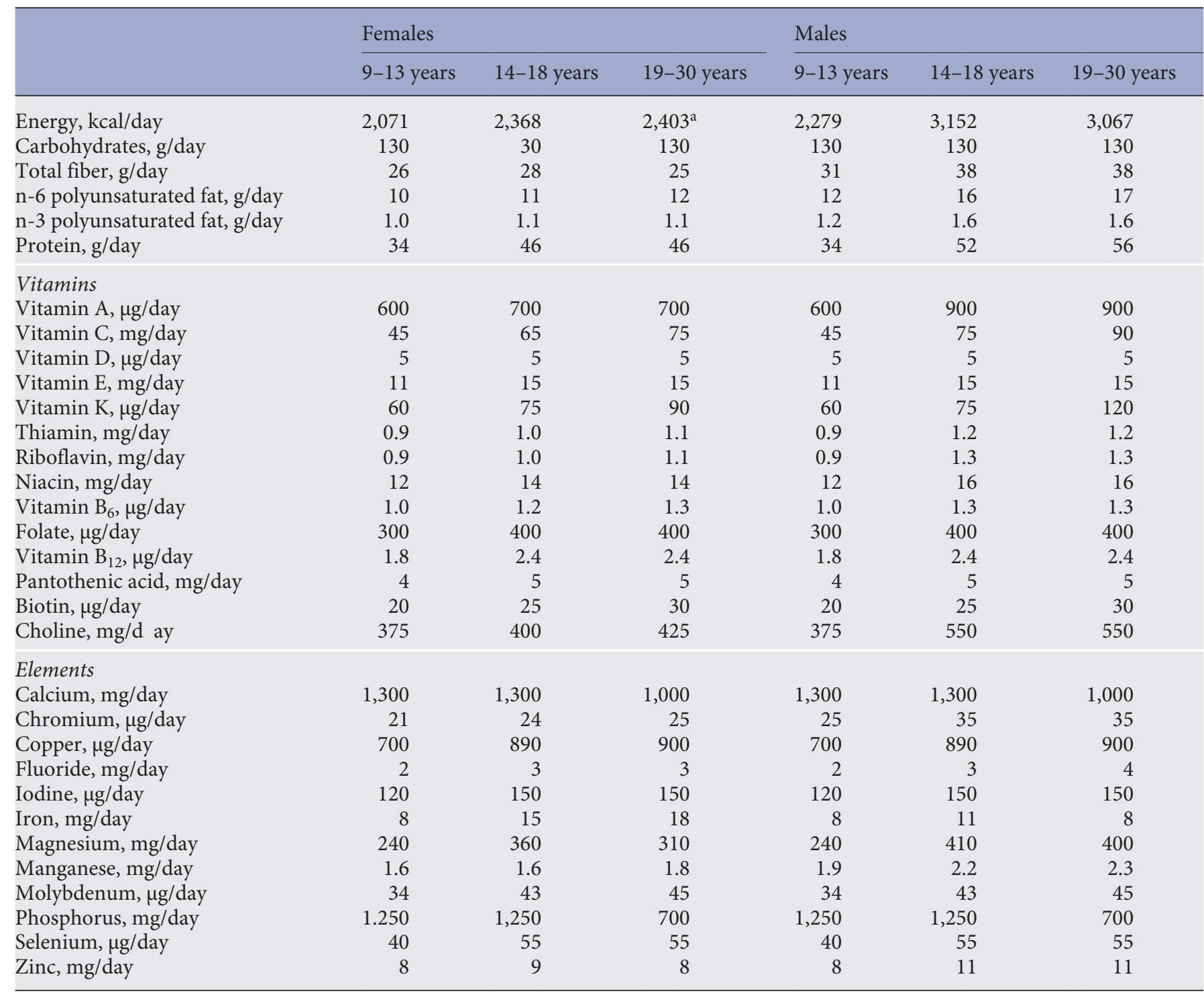

Source: data from reports from the Institute of Medicine, Food and Nutrition Board, Standing Committee on the Scientific Evaluation of Dietary Reference Intakes, copyright by the National Academy of Sciences, courtesy of the National Academies Press, Washington, DC, USA (http://www.nap.edu/).

changes [21]. Undernutrition provokes stress in the body and stimulates the release of adrenaline and noradrenaline and the production of cortisol. The chronic physiological stress due to undernutrition over time weakens the body and leads to fatigue and unproductivity and also poses multiple-fold risks of getting an infection [22]. A study on malnourished children found a higher resting heart rate [23] and an association of nutritional stunting with increased rates of arterial hypertension [24, 25]. Short maternal stature is associated with obesity and type 2 diabetes [26], low birth weight, and stunting in children [27]. Undernutrition is also linked with hyperinsulinemia and reduced sensitivity to insulin, which is responsible for an increased BMI in adult life [28]. Animal studies have also proven that changes in in utero kidney development can occur due to maternal malnutrition and sug- 
gested delays in intrauterine growth and a reduced number of nephrons [29]. This phenomenon determines poor renal function and increased blood pressure. Studies have also shown the association of pancreatic function with undernutrition in early life [30]. Undernutrition and ensuing anemia can also effect cognitive development, the ability to learn, and hence compromise the standard of living throughout the life cycle [31].

Evidence suggests that a poor maternal BMI before and during pregnancy has significant impacts on adverse pregnancy outcomes. A recent review reported that maternal prepregnancy underweight is significantly associated with preterm births, small-for-gestational-age babies and low birth weight [32]. On the other hand, maternal pre-pregnancy overweight is associated with increased risk of hypertensive disorders, pre-eclampsia, and gestational diabetes. The risk of adverse pregnancy outcomes increases multifold if the mother is obese [32].

Similarly, overweight and obesity among children and adolescents pose an increased risk for cardiovascular and other noncommunicable diseases. There is considerable evidence to show that childhood obesity is a risk factor for type 2 diabetes, hypertension, coronary heart disease, and stroke in adulthood (hazard ratios ranging from 1.1 to 5.4) $[33,34]$. A systematic review of 23 studies reported that childhood obesity is significantly associated with adult systolic and diastolic blood pressure and triglycerides and inversely associated with high-density lipoprotein [35]. And hypertension is the leading cause of other noncommunicable diseases, such as high serum cholesterol, diabetes, etc. These also lead to direct (medical) and indirect (nonmedical) costs related to obesity that impose a significant economic burden to individuals and health care infrastructure.

\section{Nutrition Interventions for Older Children and Adolescents}

Intervening in infancy and early childhood is paramount to improving the nutritional status and achieving long-lasting impacts as this is an age group which responds well to the interventions not only to improve physical growth but also cognitive development and attainment of complete physical capacity. Various interventions including optimal breastfeeding, complementary feeding, and micronutrient supplementation have been recommended for infants and young infants. Apart from nutrition-specific interventions, water, sanitation, hygiene, and prevention of infection also play an important role [36]. Although older children and adolescents
Table 2. Evidence of impact of interventions in older children

\begin{tabular}{|c|c|}
\hline Outcome & Impact \\
\hline \multicolumn{2}{|l|}{ School feeding programs } \\
\hline \multicolumn{2}{|l|}{ Weight gain } \\
\hline Over 19 months & MD: $0.39 \mathrm{~kg}$ (95\% CI: 0.11 to 0.67$)$ \\
\hline Over 11.3 months & MD: $0.71 \mathrm{~kg}$ (95\% CI:0.48 to 0.95$)$ \\
\hline Height gain & MD: $0.38 \mathrm{~cm}(95 \% \mathrm{CI}:-0.32$ to 1.08$)$ \\
\hline \multicolumn{2}{|l|}{ Micronutrient powders } \\
\hline Anemia & RR: 0.53 (95\% CI: 0.25 to 1.12$)$ \\
\hline Hemoglobin & MD: $7.86 \mathrm{~g} / \mathrm{L}$ (95\% CI: -0.76 to 16.49$)$ \\
\hline \multicolumn{2}{|c|}{ Intermittent iron supplementation } \\
\hline Anemia & RR: 0.54 (95\% CI: 0.33 to 0.90$)$ \\
\hline Hemoglobin & MD: $4.04 \mathrm{~g} / \mathrm{L}$ (95\% CI: 0.30 to 7.78$)$ \\
\hline \multicolumn{2}{|l|}{ Iron fortification } \\
\hline Hemoglobin & SMD: 0.46 (95\% CI: 0.24 to0.67) \\
\hline Anemia & RR: 0.60 (95\% CI: 0.43 to 0.84$)$ \\
\hline \multicolumn{2}{|c|}{$M M N$-fortified beverages } \\
\hline Hemoglobin & MD: 2.76 g/L (95\% CI: 1.19 to 4.33 ) \\
\hline Anemia & RR: 0.58 ( $95 \%$ CI: 0.29 to 0.88$)$ \\
\hline Iron deficiency anemia & RR: 0.17 (95\% CI: 0.06 to 0.53 ) \\
\hline
\end{tabular}

$\mathrm{MD}$, mean difference; $\mathrm{MMN}$, multiple micronutrient; $\mathrm{RR}$, risk ratio; $\mathrm{SMD}$, standard mean difference.

often do not receive intervention and policy priority, intervening in this age is also vital for improving nutrition and achieving long-term health. A balanced, nutritious diet is the key to promote healthy growth and development of children and adolescents [37], leading to a healthier and productive generation. Below we discuss the evidence-based nutrition-specific interventions for older children (Table 2) and adolescents. Younger adolescents (10-13 years) act as a special group, as they transition from older school-aged children to adolescents.

\section{Older Children}

The interventions range from addressing under- to overnutrition. A systematic review on school feeding programs reported that balanced school meals provided in LMICs had a significant impact on weight but not on height [38]. Multiple micronutrient supplementation through fortified beverages has shown a significant impact on improving serum hemoglobin level and reducing the risk of anemia in school-aged children in low-resource settings [39]. A systematic review on micronutrient powders suggested an impact on improving serum hemoglobin and reducing the prevalence of anemia in
Das/Lassi/Hoodbhoy/Salam 
children under the age of 5 years but not in older children [40]. A systematic review on intermittent iron supplementation in children aged 5-10 years showed a statistically significant increase in serum hemoglobin but no effect on anemia, and this review also suggested no difference when intermittent iron supplementation was compared to daily supplementation [41]. A review on iron fortification also suggested improvement in serum hemoglobin levels and reduction in anemia in preschooland school-aged children [42]. There is some evidence suggesting that iodine supplementation in children aged 10-12 years leads to improvement in cognitive functioning and fine motor skills [43].

A review on interventions to prevent obesity in older children through altering dietary or physical activity-related factors, or both suggested a reduction in BMI with interventions predominantly based on behavior change theories and implemented in education settings [44]. There is some evidence that school-based physical activity interventions lead to an improvement in engagement in moderate to vigorous physical activity during school hours (odds ratio: 2.74, 95\%

The combination of various settings can be proposed as one of the solutions to effectively address nutritional interventions in older children and adolescents
A recent systematic review of nutrition interventions in adolescents suggested that iron/iron folic acid supplementation alone or in combination with other micronutrients leads to a reduction in anemia (risk ratio: 0.69, 95\% CI: 0.62 to 0.76 ) and was associated with improved serum hemoglobin (MD: $1.94 \mathrm{~g} / \mathrm{dL} ; 95 \%$ CI: 1.48 to 2.41 ), ferritin (MD: $3.80 \mu \mathrm{g} / \mathrm{L} ; 95 \% \mathrm{CI}: 2.00$ to 5.59), and iron (MD: $6.97 \mathrm{mmol} / \mathrm{L} ; 95 \% \mathrm{CI}: 0.19$ to 13.76 ) [51]. Zinc supplementation led to improved serum zinc concentrations (MD: $0.96 \mu \mathrm{g} / \mathrm{dL} ; 95 \% \mathrm{CI}: 0.81$ to 1.12 ), while calcium and vitamin D supplementation did not have a clear impact on vitamin D levels or parathyroid hormone [51].

The nutritional effect of large-scale urbanization, often coined the "nutrition transition," is that as people assume a more sedentary lifestyle, have more ready access to snack or street foods, and reduce the consumption of more traditional foods, the prevalence of overweight and obesity increases substantially. As increased caloric input is one of the key mechanisms for weight gain, nutritional interventions are a key for preventing and managing obesity in adolescents. Interventions targeted to adolescents to improve fruit and vegetable consumption behaviors suggest that these behaviors are dependent on home availability of fruits/vegetables and taste preferences [52]. A positive correlation between milk consumption and bone mineral density has also been reported in young girls [53]. Dietary interventions for obesity management in adolescents include caloric restriction [54] and/or traffic light diet (low added sugar and increased fiber intake) [55], which have shown to have significant reductions in BMI and waist circumference [56]. The NEAT (Nutrition and Enjoyable Activities in Teen Girls) trial to prevent obesity in girls from a low socioeconomic background reported an insignificant effect on body composition but may still have potential clinical importance [57].

\section{Intervention Delivery}

Several platforms have been used to deliver nutrition interventions to older children and adolescents. These include schools, community groups, youth organizations, health centers, and mass media [58]. Schools have been the main medium that has been used and has been effective to deliver nutrition interventions. Electronic and social media platforms have gained much popularity over the years as a way to reach a vast number of youth. Mass media campaigns using television and radio have the po- 
tential to improve dietary quality in youth [59]. mHealth technology has also been studied to promote a healthy diet and other lifestyle behaviors in children [60]. A recent systematic review reported that compliance to treatment and self-monitoring has been shown to improve with the use of this technology; however, the effect on outcomes such as BMI was limited [60]. A combination of various platforms such as schools, community, and media has been successful in implementing healthy dietary patterns in elementary-school children [61]. The combination of various settings can be proposed as one of the solutions to effectively address nutritional interventions in older children and adolescents.

\section{Conclusion}

Adolescent and older children health care is challenging compared to that of children under the age of 5 years and adults, and this is due to various factors mostly related to the ever-evolving physical and mental development. There is still a high burden of malnutrition in older children and adolescents globally, with developed countries facing a huge load of overweight and obesity, while developing countries are engulfed with a traditionally high prevalence of undernutrition and the threats of recent hike in overweight and obesity. There is a greater need to focus exclusively on this population, as improving the nutritional status of adolescents can help break the vicious cycle of intergenerational malnutrition. National governments together with development partners need to make specific guidelines and recommendations to tackle malnutrition in this age group, albeit this may require more evidence especially around determining strategies to combat obesity. This focus would not only improve the nutritional status of older children and adolescents but may also escalate the mental and cognitive growth and help individuals reach their true potential, which may have far-reaching repercussions by not only increasing the quality of life but influence the growth and productivity of generations to come and countries at large.

\section{Disclosure Statement}

All authors declare no conflict of interest and received no compensation. The writing of this article was supported by Nestlé $\mathrm{Nu}$ trition Institute.

\section{References}

1 Karnik S, Kanekar A: Childhood obesity: a global public health crisis. Int J Prevent Med 2012;3:1.

2 WHO: Obesity and overweight factsheet from the WHO. Health 2018. Available at http:// www.who.int/mediacentre/factsheets/fs311/ en/.

$3 \mathrm{Ng} \mathrm{M}$, Fleming T, Robinson M, Thomson B, Graetz N, Margono C, Mullany EC, Biryukov S, Abbafati C, Abera SF: Global, regional, and national prevalence of overweight and obesity in children and adults during 1980-2013: a systematic analysis for the Global Burden of Disease Study 2013. Lancet 2014;384:766-781.

4 Global Burden of Disease Pediatrics Collaboration, Kyu $\mathrm{HH}$, Pinho C, Wagner JA, Brown JC, Bertozzi-Villa A, Charlson FJ, Coffeng LE, Dandona L, Erskine HE, et al: Global and national burden of diseases and injuries among children and adolescents between 1990 and 2013: findings from the Global Burden of Disease 2013 study. JAMA Pediatr 2016;170: 267-287.

5 UNPFA: The State of World Population: Motherhood in Childhood. Facing the Challenge of Adolescent Pregnancy. New York, United Nations Population Fund, 2013.
6 Kurz KM: Adolescent nutritional status in developing countries. Proc Nutr Soc 1996;55(1B): 321-331.

7 Martorell R, Zongrone A: Intergenerational influences on child growth and undernutrition. Paediatr Perinat Epidemiol 2012;26(s1):302314.

8 Neufeld LM, Haas JD, Grajéda R, Martorell R: Changes in maternal weight from the first to second trimester of pregnancy are associated with fetal growth and infant length at birth. Am J Clin Nutrn 2004;79:646-652.

9 Gale CR, O'Callaghan FJ, Godfrey KM, Law CM, Martyn CN: Critical periods of brain growth and cognitive function in children. Brain 2004;127:321-329.

10 Salam RA, Das JK, Bhutta ZA: Impact of intrauterine growth restriction on long-term health. Curr Opin Clin Nutr Metab Care 2014;17:249-254.

11 Sato APS, Fujimori E, Szarfarc SC, Borges ALV, Tsunechiro MA: Food consumption and iron intake of pregnant and reproductive aged women. Rev Lat Am Enfermagem 2010; 18:247-254.

12 Balarajan Y, Ramakrishnan U, Özaltin E, Shankar AH, Subramanian S: Anaemia in low-income and middle-income countries. Lancet 2012;378:2123-2135.
13 Black RE, Allen LH, Bhutta ZA, Caulfield LE, De Onis M, Ezzati M, Mathers C, Rivera J Maternal and Child Undernutrition Study Group: Maternal and child undernutrition: global and regional exposures and health consequences. Lancet 2008;371:243-260.

14 Allen LH, Gillespie SR: What Works? A Review of the Efficacy and Effectiveness of Nutrition Interventions. Asian Development Bank, 2001.

15 Konje JC, Ladipo OA: Nutrition and obstructed labor. Am J Clin Nutr 2000;72:291s-297s.

16 Cole TJ, Bellizzi MC, Flegal KM, Dietz WH: Establishing a standard definition for child overweight and obesity worldwide: international survey. BMJ 2000;320:1240-1243.

17 Rogol AD, Clark PA, Roemmich JN: Growth and pubertal development in children and adolescents: effects of diet and physical activity. Am J Clin Nutr 2000;72:521s-528s.

18 Ransom EI, Elder LK: Nutrition of women and adolescent girls: why it matters. Population Reference Bureau, 2003.

19 Nweneka CV, Doherty CP, Cox S, Prentice A: Iron delocalisation in the pathogenesis of malarial anaemia. Trans R Soc Trop Med Hyg 2010;104:175-184. 
20 Bhandari N, Mazumder S, Bahl R, Martines J, Black RE, Bhan MK: Use of multiple opportunities for improving feeding practices in under-twos within child health programmes. Health Policy Plan 2005;20:328-336.

21 Martins VJ, Toledo Florencio TM, Grillo LP, do Carmo PFM, Martins PA, Clemente AP, Santos CD, de Fatima AVM, Sawaya AL: Long-lasting effects of undernutrition. Int J Environ Res Public Health 2011;8:1817-1846.

22 Manary MJ, Muglia LJ, Vogt SK, Yarasheski KE: Cortisol and its action on the glucocorticoid receptor in malnutrition and acute infection. Metabolism 2006;55:550-554.

23 Bedi M, Babbar R, Chakrabarty A, Sachdev $\mathrm{H}$ : Comparative study of autonomic nervous system activity in malnourished and normal children in India. Ann Trop Paediatr 1999; 19:185-189.

24 Fernandes MTB, Sesso R, Martins PA, Sawaya AL: Increased blood pressure in adolescents of low socioeconomic status with short stature. Pediatr Nephrol 2003;18:435-439.

25 Florêncio T, Ferreira H, Cavalcante J, Sawaya A: Short stature, obesity and arterial hypertension in a very low income population in north-eastern Brazil. Nutr Metab Cardiovasc Dis 2004;14:26-33.

26 Ferreira HS, Moura FA, Júnior CRC, Florêncio TM, Vieira RC, de Assunçao ML: Short stature of mothers from an area endemic for undernutrition is associated with obesity, hypertension and stunted children: a population-based study in the semi-arid region of Alagoas, Northeast Brazil. Br J Nutr 2008;101: 1239-1245.

27 Nicklas BJ, Cesari M, Penninx BW, Kritchevsky SB, Ding J, Newman A, Kitzman DW, Kanaya AM, Pahor M, Harris TB: Abdominal obesity is an independent risk factor for chronic heart failure in older people. J Am Geriatr Soc 2006;54:413-420.

28 González-Barranco J, Rios-Torres J, CastilloMartınez L, López-Alvarenga J, Aguilar-Salinas C, Bouchard C, Depres J, Tremblay A: Effect of malnutrition during the first year of life on adult plasma insulin and glucose tolerance. Metabolism 2003;52:1005-1011.

29 Hinchliffe S, Lynch M, Sargent P, Howard C, Velzen Dv: The effect of intrauterine growth retardation on the development of renal nephrons. Br J Obstet Gynaecol 1992;99:296301.

30 Breant B, Gesina E, Blondeau B: Nutrition, glucocorticoids and pancreas development. Horm Res Paediatr 2006;65(suppl 3):98-104.

31 Ross J, Horton S, Initiative M: Economic Consequences of Iron Deficiency: Micronutrient Initiative, IDRC, Ottawa, 1998.

32 Dean SV, Lassi ZS, Imam AM, Bhutta ZA: Preconception care: nutritional risks and interventions. Reprod Health 2014;11:S3.

33 Park MH, Falconer C, Viner RM, Kinra S: The impact of childhood obesity on morbidity and mortality in adulthood: a systematic review. Obes Rev 2012;13:985-1000.
34 Reilly JJ, Kelly J: Long-term impact of overweight and obesity in childhood and adolescence on morbidity and premature mortality in adulthood: systematic review. Int J Obes 2011;35:891-898.

35 Umer A, Kelley GA, Cottrell LE, Giacobbi P, Innes KE, Lilly CL: Childhood obesity and adult cardiovascular disease risk factors: a systematic review with meta-analysis. BMC Public Health 2017;17:683.

36 Bhutta ZA, Das JK, Rizvi A, Gaffey MF, Walker N, Horton S, Webb P, Lartey A, Black RE; Lancet Nutrition Interventions Review Group, the Maternal and Child Nutrition Study Group: Evidence-based interventions for improvement of maternal and child nutrition: what can be done and at what cost? Lancet 2013;382:452-477.

37 WHO: Diet, Nutrition and the Prevention of Chronic Diseases: Report of a Joint WHO/ FAO Expert Consultation. WHO Technical Report Series 916. Geneva, World Health Organization, 2003.

38 Kristjansson E, Robinson V, Petticrew M, MacGowan J, Farmer A, Shea B: School feeding for improving the physical and psychosocial health of disadvantaged elementary school children. Cochrane Database Syst Rev 2006:CD004676.

39 Aaron GJ, Dror DK, Yang Z: Multiple-micronutrient fortified non-dairy beverage interventions reduce the risk of anemia and iron deficiency in school-aged children in lowmiddle income countries: a systematic review and meta-analysis (i-iv). Nutrients 2015;7: 3847-3868.

40 De-Regil LM, Jefferds MED, Pena-Rosas JP: Point-of-use fortification of foods with micronutrient powders containing iron in children of preschool and school-age. Cochrane Database Syst Rev 2017:CD009666.

41 De-Regil LM, Jefferds ME, Sylvetsky AC, Dowswell T: Intermittent iron supplementation for improving nutrition and development in children under 12 years of age. Cochrane Database Syst Rev 2011:CD009085.

42 Das JK, Salam RA, Kumar R, Bhutta ZA: Micronutrient fortification of food and its impact on woman and child health: a systematic review. Syst Rev 2013;2:67.

43 Zimmermann MB, Connolly K, Bozo M, Bridson J, Rohner F, Grimci L: Iodine supplementation improves cognition in iodine-deficient schoolchildren in Albania: a randomized, controlled, double-blind study. Am J Clin Nutr 2006;83:108-114.

44 Waters E, de Silva-Sanigorski A, Hall BJ, Brown T, Campbell KJ, Gao Y, Armstrong R, Prosser L, Summerbell CD: Interventions for preventing obesity in children. Cochrane Database Syst Rev 2011:CD001871.

45 Dobbins M, Husson H, DeCorby K, LaRocca RL: School-based physical activity programs for promoting physical activity and fitness in children and adolescents aged 6 to 18. Cochrane Database Syst Rev 2013:CD007651.
46 Evans CE, Christian MS, Cleghorn CL, Greenwood DC, Cade JE: Systematic review and meta-analysis of school-based interventions to improve daily fruit and vegetable intake in children aged 5 to $12 \mathrm{y}$. Am J Clin Nutr 2012;96:889-901.

47 James J, Thomas P, Cavan D, Kerr D: Preventing childhood obesity by reducing consumption of carbonated drinks: cluster randomised controlled trial. BMJ 2004;328:1237.

48 WHO: Iron deficiency anaemia: assessment, prevention, and control. A guide for programme managers. World Health Organization, 2001. Available from: http://whqlibdoc. who.int/hq/2001/WHO_NHD_01.3.pdf.

49 WHO: Prevention of neural tube defects: integrated management of pregnancy and childbirth. Standards for Maternal and Neonatal Care. 2002 Available from: http://www. who.int/making_pregnancy_safer/publications/Standards1.

50 Rodríguez-Rodríguez E, Navia Lombán B, López-Sobaler AM: Review and future perspectives on recommended calcium intake. Nutrición Hospitalaria 2010;25.

51 Salam RA, Hooda M, Das JK, Arshad A, Lassi ZS, Middleton P, Bhutta ZA: Interventions to improve adolescent nutrition: a systematic review and meta-analysis. J Adolesc Health 2016;59(4S):S29-S39.

52 Neumark-Sztainer D, Wall M, Perry C, Story M: Correlates of fruit and vegetable intake among adolescents: findings from project EAT. Prevent Med 2003;37:198-208.

53 Kim SH, Kim WK, Kang M-H: Effect of milk and milk products consumption on physical growth and bone mineral density in Korean adolescents. Nutr Res Pract 2013;7: 309-314.

54 Sondike SB, Copperman N, Jacobson MS: Effects of a low-carbohydrate diet on weight loss and cardiovascular risk factor in overweight adolescents. J Pediatr 2003;142:253258

55 Reinehr T, de Sousa G, Toschke AM, Andler W: Long-term follow-up of cardiovascular disease risk factors in children after an obesity intervention. Am J Clin Nutr 2006;84: 490-496.

56 Ho M, Garnett SP, Baur LA, Burrows T, Stewart L, Neve M, Collins C: Impact of dietary and exercise interventions on weight change and metabolic outcomes in obese children and adolescents: a systematic review and meta-analysis of randomized trials. JAMA Pediatr 2013;167:759-768.

57 Lubans DR, Morgan PJ, Okely AD, Dewar D, Collins CE, Batterham M, Callister R, Plotnikoff RC: Preventing obesity among adolescent girls: one-year outcomes of the Nutrition and Enjoyable Activity for Teen Girls (NEAT Girls) cluster randomized controlled trial. Arch Pediatr Adolesc Med 2012;166: 821-827. 
58 Bhutta ZA, Lassi ZS, Bergeron G, Koletzko B, Salam R, Diaz A, McLean M, Black RE, Rigil LM, Christian P: Delivering an action agenda for nutrition interventions addressing adolescent girls and young women: priorities for implementation and research. Ann NY Acad Sci 2017;1393:61-71.
59 Hieftje K, Edelman EJ, Camenga DR, Fiellin LE: Electronic media-based health interventions promoting behavior change in youth: a systematic review. JAMA Pediatr 2013;167: 574-580.

60 Turner T, Spruijt-Metz D, Wen CF, Hingle MD: Prevention and treatment of pediatric obesity using mobile and wireless technologies: a systematic review. Pediatr Obes 2015; 10:403-409.
61 Alaimo K, Carlson JJ, Pfeiffer KA, Eisenmann JC, Paek H-J, Betz HH, Thompson T, Wen Y, Norman GJ: Project FIT: a school, community and social marketing intervention improves healthy eating among low-income elementary school children. J Commun Health 2015;40:815-826. 